\title{
The long arm of the sustainable port
}

\author{
Bartłomiej Laskowski*
}

\begin{abstract}
As there has been a lot written regarding sustainable transportation methods, there is still some opportunity to enhance the perspective on the economic advantage of the zero-emission supply chain. This has the potential of an accelerated adaptation in a cost to serve delivery system. The paper will introduce into the discussion the concept of working with nature, to develop durable structures and its capability of delivering value on its interactive environment or face the natural selection process. The functionality of the Port will be revisited in contrast of today's confinements of operation, while creating an opportunity to strengthen its perspective on its deliverables and reassess today's market. Further it will reflect whether sustainable transportation planning is still a choice or a competitive requirement.
\end{abstract}

\section{Research Goal}

To describe the delegating role of ports on the sustainability development in the port's hinterland access by inland waterway corridors

\subsection{Methodology}

The research is a qualitative analysis of prescriptive methodologies on sustainable development, offering a problem definition, diagnosis, design and implementation, concluded by the research results.

Limitation of research is the lack of quantitative data available for the application of some of the resent management methods, therefore the limitation is an evaluation of applying some of these methods to a corridor's social development.

- The problem definition is introduced in chapter, the function of a port.

- The diagnostic of issue identification and interventions is introduced in the chapter, Justifying the business purpose.

- The design to addresses the issues and application of the interventions is elaborated in the chapter, Equilibrium in institutional relationships.

\footnotetext{
* Corresponding author: Bartlomiej.Laskowski@outlook.com
} 
- In the application and opportunity chapters, the implementation of the changes and engaging intervention participation are discussed.

\section{The function of the Port}

The traditional function of the port is that of connecting means of transition.

Yet the classical models of measuring the ports value, is that of revenue streams and its effectiveness is depicted by how much throughput it can accommodate in a specific period.

However, Ports are connecting much more than just modalities, thus the emphasis should be more on the term transition. Although the competitiveness that attracts foreign direct investment can be measured by how well connected throughput streams are. This measuring model is still evolving.

Today's challenge is to be able to reduce the cost to serve. This attracts a foreign entities investment and improves the regional economical capability to deliver productivity. This offers opportunities to reflect on the standard.

Companies are continuously challenging their throughput streams on their involved modalities, by identifying the optimal supply stream of production to its consumer. Thereby, allocating cost-efficient throughput along the available modal split. In this perspective, the key would be flexibility to mitigate between the available modality options of the market one is trading in. Balance its market shocks, risks and maximize present market advantages, allowing the market forces to synchronize its modal split utilization. This can be referred to as, synchro modal optimization of the available transport portfolio.

In this perspective, a sustainable port is one that offers efficiency on the supply chain as the entry and exit point of an overall economy. It should be integrated with a transportation modality that offers energy efficiency on the work performed. Thus, a sustainable infrastructure mechanism with the port having a delegating entry and exit position to that system. A transfer point from the sea to the land as an exchange chokepoint.

The article Chokepoints in Corridors: Perspectives on bottlenecks in the European transport network, by Patrick Witte et al. (2012) elaborates that in Europe a lack of thorough understanding of bottlenecks and their cumulative effects on each other is lacking in the transport network.

"The findings from Patrick Witte's research have indeed identified that cumulative accelerator affects exist in the current conduct of logistical interaction between the user groups and planning bodies of the infrastructures. It also identified that the interactions and effects between these user groups are far wider and more complex than the traditional dimensions of infrastructure and spatial structure perspectives, as such the subject of chokepoints or bottlenecks deserves in today's fast pace environment a wider and more complex recognition to the fields it is interacting with." [1]

He points out the interaction between the realms of infrastructure, spatial structure, governance structure and economical structure through interaction of their sub dimensional categories, have the ability to cumulate and accelerate effects of bottlenecks.

Witte's concept offers the possibility for issue identification on trade corridors.

Understanding the issue to be exposed is crucial, as it is said by Copernicus:" To know that we know what we know, and to know that we do not know what we do not know, that is true knowledge."

As previously stated Ports have a connecting function, as such they have the ability to connect interaction with its surrounding potential.

"The main challenge today is to implement and develop methods that improve the environment and strengthen the economy simultaneously by making optimal use of the available space.” Waterman (2015) 
Such a space is not merely reserved for connecting the tangible throughput streams.

This can also be exposed in the Ports ability to connect interdependencies of corridors and even the ability to intertwine with the economic entanglement by creating shared values and with that connecting human capital that can drive the knowledge economy. A system that is perfectly mature where its boundaries of optimal utilization have been reached, does not offer a driving competitiveness, it drives only an idle state of progress stagnation.

\subsection{Problem definition}

The problem definition is the ports immature market potential from improving the environment and strengthening the economy, by making optimal use of the available space in it's hinterland network.

\section{Justifying the business purpose}

A perfect system that has had its potential already exposed, will not create growth or progress. This is left to a system with build in failures at critical points to create continues iterative regeneration on comfortability, in order to generate process resilience and counter stagnation of progress.

Such a system can create assimilation into its surrounding circumstances of the micro economies of Ports and enable durable competitive investments. This iterative development of resilience fosters commitment in harmony of its macroeconomic opportunity spectrum.

Porter and Kramer have described in their articles, The Big idea creating shared value and measuring shared Value (2011) the concept of a self-reflecting system. Their shared value concept describes a different type of business conduct. One where social and community challenges and are part of the professional business conduct. After all, "strategy theory holds that to be successful, a company must create a distinctive value proposition that meets the needs of a chosen set of customers." According to this, not only the economic needs but also social requirements, specify the composition of a market. Their work reflects the cooperate social responsibility applications in perspective to creating shared value. Today it is understood by the CSR concept that social or community issues are not the main concern of a classical company. In general, the view persists that external institutions outside of a company, force an internal financial strain on the business conduct. A lack of awareness of available concepts creates the perception that social costs are externalities, that are only an additional general cost of running a business. Governmental institutions are also not supportive in developing a modern perception. They see business to have a short-term orientation, with the perception to internalize social costs on companies by using taxes as an instrument. Having only one instrument that is typically associated with a punishing function in order to attempt internalizing social costs, companies are driven to take a defensive stand against the social responsibility approach, experiencing it as to only generate additional costs. This leads unfortunately to companies refraining from embracing the needs and challenges in societies to be included in their business opportunity perception, that otherwise generate costs on governments. $[7,8]$

"It is an unfortunate issue, as companies fail to grasp the importance of their broader business environment, surrounding their major operations. Without this understanding the opportunity to connect competitive advantage and societal issues is missing. By reconceiving products and markets, redefining productivity in the value chain and enabling local cluster development, companies can reposition themselves to generate shared values on societies for a sustainable business relationship. 
To sum it up the business conduct concept to be delivered should offer a prosperity benefit to the societal stakeholders that than yields itself in the form of growth feeding back into the business, as such one could compare it to a product life cycle that instead of having a maturity and decline phase, it would be part of a circular economy with its society forming an ecosystem by creating shared Value." [1]

Measuring of shared value itself, is done on three pillars:

- Reconceiving products and markets, is an orientation level that analyses the outer self of the business, the perception of the business by other external parties. It focuses on the business factors that can be yielded from the shared value creation approach.

- Redefining productivity in the value chain, is an analysis of the internal self of the business conduct, when considering the environmental and social focus areas, exposing opportunities for the internal operating process.

- Enabling local cluster development, is the output level. The shaping of the immediate/local physical area of influence in a mutual beneficial symbiotic relation to benefit the local area with consideration of the environment and social prosperity for the business. [8]

Ports facilitate an economic region's prerequisite to get the goods in and out, in the most efficient way. Thereby this process optimisation is supporting the Port's network maximization.

Exposing plans that have been proven through the test of time, can be identified in history.

These durable alternations, can form the conduct of the future. They require commitment and financing, that in turn can yield its own revenues. These revenues can be outside of the financial realm and support the attractiveness of the waterfront revenue and spatial quality.

A thorough evaluation of the finances is required, from initial financing, operational expenses to maintenance cost. The success of such plans requires the harmonization of activities between institutions such as, local regional and central governments, actors in the private sector and research and educational institutions together with environmental and landscaping societies. [4,5]

Where Patrick Witte's chokepoint on corridors exposes issues in corridors, Watermans and Brouwers Aquapuncture concept offers solutions and actions on these issues with regards to stakeholder's user groups. They do this by exposing the complex interaction of effects a waterfront intertwined balance of entanglement has on its society and environment.

It is remarkable how self-sustaining yet delicate such a balance can be, suspended in the interaction of external forces acting upon it.

\section{Equilibrium in institutional relationships}

Due to the changing nature of the morphological environment, that is continuously trying to adapt to the new equilibrium of it's surrounding. It is crucial in order to yield the full functional potential of the available space, to apply strategical planning of the functionality requirements.

Even ideas that follow an economic logic, are at risk to be rejected if they do not generate practical value for its participant and stakeholders, within their own surrounding.

One can compare it to a natural ecosystem, that has a new item introduced to interact with. As soon as it does not offer any value to the ecosystem and its inhabitants, the system either rejects it, or generates more efficient alternatives for it.

Nature has thus already set the tone, that for any long term project to be acceptable, a sustainable business model is required. Such a project, is to find a value fit with the societies it is expected to be in a long term interaction with. In turn the accepted models are less invasive when introduced, as these societies are already more receptive to that local configuration to the environmental equilibrium. 
Sustainable development projects require long terms investments, that are dependent on sustainable relationships. Even a sustainable project that is not in balance with the institutional interaction, is a possible investment risk. The time constraining transitions of perception and interaction on trade corridor conduct effecting Port investments, require stable relationships.

A significant philosopher dedicated to observing truth was Baruch Spinoza in his works of the Ethics as elaborated by R. Prokhovnik's work Spinoza and Republicanism (2004). Prokhovnik elaborates that Spinoza moved from the notion of balance to be the principle of tolerance between extremes nor did he recognize the golden mean argument. Instead he suggests an equilibrium of the suspension on a moving interaction between actors according to their proportions. As such: "For Spinoza a balance of government or politics represents a group of people, not necessarily in an electoral sense, but as a constituency nevertheless. The critical point for Spinoza is that when a fitting proportion creates balance, things are held in dynamic tension, in balance rather than equal with one another. For Spinoza, this balance is a principle of anti-corruption."

Therefore, one can conclude that balance is the harmonization of dynamic interactive tension between the actors in regard to their values, as Spinoza (1632 Amsterdam-1677 The Hague) concluded so fitting: "On balance I prefer to preserve the etymological connection between affectio and afficere"

Van Tulder and Pfisterer have developed a Taxonomy process on some of these institutional forces acting upon each other. They did this to understand the nature of the current institutional actor's suspension of forces and what does this suspension say on the suitability of possible partnership types. Their article "Creating partnering space" has been motivated by misalignment of action owners, due to the lack of identifying roles to actors in partnership management of sustainable development. This fit on institutional interaction is exposed by the growing knowledge on the conditions, that are needed in sustainable development. Such partnership management is common between the Government, the private sector and civil societies organisations.

Understanding the powerbases of the institutional actors can expose their positioning in the virtual partnering space, which in turn can state something on the delegating role of the Ports partnership program in regard to its inland waterway program, be it for example a public private partnership interacting with a Profit-non-profit partnership.

Misalignment of such relationship often occurs in these bilateral perspectives crowding out one of the parties possibly adding to the institutional divide. A partnership relationship that includes the Government, the private sector and the civil society organisations requires a thorough understanding of the positioning of their roles.

Van Tulder and Pfisterer describe that in order to create an effective partnership with the actors involved in sustainable development, their partnering space can be exposed by asking the following questions:

1. What defines the "space ${ }^{e e}$ in which partnerships develop to address sustainable development issues?

2. What kind or relevant roles do parties bring into the partnership?

3. What does this imply for the organizational fit of the parties in partnering space?

4. How does the various degrees of fit contribute to sustainable development?

5. They conclude by questioning whether there is an ,optimal fit ${ }^{e e}$ at all?

These fundamental questions, drive a collaboration, that is focused on the effects it has on the society it interacts with. An evolution from the traditional models that focus on benefiting the individual partners. These Cross-sector social partnerships (CSSPs) have the potential to drive modern socioeconomic development models. This type of relationship 
interaction is held in perspective to its feasibility on its societal orientation. For complex intertwined long term relationships, as in sustainable projects, a cross-sectorial social partnership can be considered to be a required management system.

In reflection of this, one can argue that the alignment balance of institutional actors is represented by regional societal values, when confronted with a set of objectives. One can conclude the observation, that a right balance differs from the perception of values. This is dependent on the driving actors to the objectives from each societal region, whether that region is defined by culture, sovereignty, state or other expression of unity in a specific region depending on the corridor. Therefore, each balance perspective is only applicable for a particular corridor and a specific suspension of harmonized tension between actors, the affectio and their conceptualized effects presented by their action items, as the afficare for the observer's consideration, being the right balance in that suspension of state.

\section{Application}

An approach of mutual interaction, has yielded already many successful results on the international stage in the development of waterfronts. This management style, focusses on facilitating stakeholders to improve their mutual productivity, thereby exposing opportunities to mitigate the challenges of logistical chokepoints.

Such mutual interaction to develop mutual productivity, is based on developing thriving conditions for its stakeholders. These conditions require a base to be developed, fostering complexity and resilience. Such a thriving ecosystem is built on a fundament, that can sustain new complexity adaptations to the interspecies communication with its environment. This communication is then made visible, by the morphological reaction over time to the environment's adaptation. After all an infrastructure or superstructure project is desired to stand the test of time with as little maintenance finance as possible.

These invasions that are introduced by man, create shocks to the environment and climate. The negative effects from these shocks have been observed to be absorbed depending on the diversity of species that is available in the area.

An area rich in diversity has the capability to be attractive for a wider group of users and therefore possible investors. A complexity sustaining area can thus facilitate a cluster of activities that in turn attracts correlated user groups.

This complexity attractiveness has provoked the settlement of people near such waterfronts, who then were facilitated by the clustering of activities to attract other types of modalities to sustain their various volume to time demands of the local distribution of goods and people.

These new business perspectives were driven by social needs, thus creating a shared value between cooperation's and social requirement. That fulfillment of a societal purpose generates opportunities for cooperation's. Allowing the profitability model of a cooperation to include social needs, unlocks the foundation of a new level of business complexity that is build on a purpose to that society, the cooperation is operating in. Such conduct unlocks new profits by harmonizing purpose. It enables a thriving society by feeding it prosperity, which in turn offers new forms of productivity to the private sector, adding to the complexity of available activities and the overall resilience by accepting circular flows of value. This puts in perspective, the value a waterfront offers as a fundament of clustering possibilities not only sustaining life itself, but facilitating the basis for new levels of complexity clusters.

One can thus observe the dependency on the variation of consumer interaction with waterfronts. The size of such clusters such as ports, can attract the interaction with other complexity clusters on the waterfront depending on a healthy water network between them to offer resilience and differentiation on consumer demand. This demand depends on the consumer need of communities, that in turn facilitate business to express that need outside of 
its local sourcing ability. The business's ability to meet that demand offers in turn favorable conditions for prosperity generation in that community. A community that has facilitated a variety of interaction, has a similar balancing effect to its environmental shocks, as previously described by the balancing effect from species diversity to an environments ability to absorb invasive shocks. A diversity of interaction modes has a favorable potential to address congestion challenges that undermine expressing the community's business needs.

The drive of facilitating an environmental fit of a local area is measurable, both in tangible and intangible effects. Physical adaptations can be measured by health and prosperity of the area's users and even of its commercial entities. An increase in complexity will result in a variety of new knowledge development areas, that in turn develop the intangible capital.

However, such growth requires a livable, attractive area for the effects to be able to manifest themselves.

These clusters of complexity based on a circular value flow, rooted in ecological prosperity, could express their community's business needs by manifesting their own organizational collaboration to absorb challenges on its logistical network nodes. These organizational collaborations have the causal effect of reducing checkpoints on these corridors, facilitating the efficiency of expressing the communities trade interaction.

\section{Opportunity}

Poland is part of the Paris MOU agreement, its Ports are operating in a region, classified by the International maritime organization as a particular sensitive sea area, referring to the Baltic sea. Therefore, it has an operating expectation on its trade conduct in regards to its port activities. As such it has a good opportunity to reflect on its goals and functional approach, rather than being subjected to a key performance indicator driven perception. Ports ought to include economic entanglement opportunities to work on behalf of their network and reach of activities.

The question a port should ask themselves, in regard to the economic entanglement growth of the knowledge based economy; has the fossil fuel infrastructure matured compared to the sustainable energy efficient infrastructure?

Think of an industry that can stimulate consumerism with a complexity to feed a spectrum of supporting industries in a circular process, feeding and nourishing each other's development. A historical example of such a system is the combustion engine. A car production would require a product lifecycle to match its required fuel supply with an additional spare part after sales industry, to support and maintain this capital investment in consumption commitment. In that the consumer would be committed to purchase fuel for 20 years. This means 20 years guaranteed repeat business. A vessel will do the same on a much larger scale per unit. Imagine than a port and its operations, as such fdi's and production intensive companies consider the energy price of their business conduct, when choosing a location to settle their activities to a new location.

In this perspective, an operational chokepoint such as a Port, has the ability to manifest a consumption unit with a low energy input on its productivity and a wide reach of supporting industries. This consideration delivers today, a competitive advantage. The most energy efficient supply chains are using transportation nodes that have already been provided by nature.

This is well described by the building with nature approach of the Aquapuncture concept by Ronald E. Waterman and Jaap Brouwer 2015a. They connect the historical tendency of civilisations to cluster on the waterfront and utilising waterways to cluster societal activities. These tendencies of slow transit systems joining rivers and lakes were globally reproduced. These core networks clustered a wide range of activities for these societies, from moving cargo and people to delivering live sustaining water for hydration and agriculture to 
maintaining flood levels. So naturally industry has settled on these time proven cluster enablers.

Due to the rise of faster modes of transferring cargo and people that were introduced to the communities and cities, the waterways have lost their perception of value. This depreciating relevance to waterway systems, came in in par with the raise of the rail and road networks. The waterways spatial structure functionality has been subjected to neglect. This neglect has exposed the sensitive relationship between the rural and urban areas these waterways kept in balance. As such their value is now being recognized with the need to revitalize these water networks.

"Improving the horizontal and vertical competition in the transportation sector should offer additional employment and offer an overall improved attractiveness for foreign direct investors, such as manufacturers to settle in established and upcoming logistical and manufacturing clusters.

A fitting quote by Professor Tadeusz Tillinger describes these interactive opportunities in relationship to waterways: "Waterways are on the one hand a part of the overall economy, and on the other hand, being an element of the transportation system, they are a part of the vascular system of the state body. It is the task of water management to channel the water falling from the sky onto the land to the sea in a way that makes it possible to minimise its harmful effects as an element and to maximise its useful properties as an indispensable matter to the lives of humans, animals and plants, as a material for transportation routes and as mass, i.e. a body with certain energy.

Marciniak (2013) describes that waterways are a part of a hole network consisting of different transport modality types. However, for bulk cargo inland waterways offer the required competitiveness. The Polish legislation states, inland waterways to be surface waters owing to the hydrological conditions and existing water devices, where inland waterway vessels can transport people and cargo under Article 9(1) (18) by the Water Law Act $18^{\text {th }}$ July 2001. In this definition, the authorities declare waterways to be navigable according to local parameters."[1]

\section{Research results}

The article connected the ports to utilize a range of modal options for specific business needs with its hinterland. It has elaborated the ports functional capacity effected by its infrastructure corridors to address the cumulative effects of congestion and organisational harmonisation. A business perspective on corporate social responsibility introduced the unmet revenue potential of circular value streams, by accepting a social and cooperate interdependency. The inclusion of various user groups and stakeholders in the development process orientation on mutual productivity, offers thriving conditions for complexity. This approach exposes objectives and action owners to work with nature, instead of continually struggling against an ecosystem trying to cope with a new equilibrium, resulting in financial strain to maintain the corridor's infrastructure and superstructure. The challenge of classical methods to mitigate sustainable partnerships have been elaborated with the introduction of creating a partnering space method, to expose the available partnering fit for a durable collaboration on long term sustainability projects. The balancing effects of environmental inclusive methodologies have been introduced to reduce internal costs and develop organisational complexity, creating new competitive capabilities for the elevated complexity availability, thereby unlocking new supporting industry requirements. The mature fossil fuel dependency and the limited growth in competitiveness it can offer on the knowledge based economy by linear value streams has been raised. This maturity has been compared to the opportunity the sustainability field offers to develop new methods of competitiveness in energy efficiency and transferring energy, while developing new skills adding to a knowledge based economy. 
This causes a correlated employment potential by connecting the horizontal and vertical competition in the transport sector. In regards of the ports competitive throughput ability of bulk loads, a direct relation has been established to the inland waterway network. That competitive capability has been connected to the polish legislative definition of inland waterways owing to the hydrological cycles and the available water devices.

\subsection{Conclusion}

As the Sea Ports are part of the hole network consisting from different types of modalities. The ports connectivity to inland waterways in regard to the Port's bulk competitiveness is owing to the hydrological conditions of such surface waters described under Article 9(1) (18). Therefore, the port as a consumption unit is a single driving force of its entanglement of supporting industries. Here competitiveness of this single unit to its alternatives is key. Energy efficiency and entwined industries, create demand from its activities while maintaining a complexity that develops barriers and niche segments on its competitors, is a way to diversify themselves and strengthen resilience. While cultures and traditions are optimally suited to their surroundings opportunities, so are their ultimate manifestations in the form of ports. Thus, it is of critical importance that these entrances as representations to their regional economic arenas are in tune with their surroundings. Prepared for the worst and negotiated for the best, as in natural selection. After all an economic environment is an ecosystem of its own with institutional actors that have their roles and functions."

\subsection{Follow up research}

It would be interesting to understand, who and if there is a liable party to the loss of revenue for local producers that are dependent on the navigability according to local parameters. Can the local authorities be held accountable for not maintaining local water devices according to the local navigability parameters, or are there even private sector parties that can be held accountable for disrupting the hydrological cycle to uphold these local parameters?

The following article uses parts and sections from the previously unpublished thesis "Balance in the Vistula's Revitalisation" by Bartłomiej Laskowski for the Master of Science in 2017 at the faculty of the Netherlands Maritime University of the STC-Group in Rotterdam the Netherlands

\section{References}

1. B. Laskowski, "Balance in the Vistula's Revitalisation", Thesis for the Master of science at the faculty of the Netherlands Maritime University of the STC-Group, Rotterdam, The Netherlands (2017)

2. $\dot{Z}$ Marciniak, Acta Energetica, 2/15 | pp. 152-161 (2013)

3. P. A. Witte a,1, B. W. Wiegmans b,1, F. G. van Oort a,2, T.J.M. Spit a,3 a) Department of Human Geography and Spatial Planning, Faculty of Geosciences, Utrecht University, Heidelberglaan 2, PO Box 80115, 3508 TC Utrecht, The Netherlands b) Department of Transport and Planning, Faculty of Civil Technology and Geosciences, Delft University of Technology, Stevinweg 1, 2628 CN Delft, The Netherlands Research in Transportation Business \& Management 5 (2012), Chokepoints in corridors: Perspectives on bottlenecks in the European transport network, pp. 57-66L. T. De Luca, Propulsion physics (EDP Sciences, Les Ulis, (2009) 
4. R. E. Waterman and Jaap Brouwer, Aquapuncture $\subset$ : Sustainable Future Of Inland Waterways, Terra et Aqua | Number 140, pp. 1-4. (2015)

5. R. E. Waterman and Jaap Brouwer 'Aquapuncture' Adaptation \& Optimal Use Of Inland Waterways And Their Waterfronts, pp. 1-8. (2008)

6. M.E. Porter and M. R. Kramer, Harvard Business Review January-February, The Big Idea, creating shared value, pp. 63-77 (2011),

7. M. E. Porter and M. R. Kramer, Foundation strategy group June, Measuring shared Value, how to unlock value by linking social and business results, pp. 1-18. (2011)

8. R. van Tulder and S. Pfisterer 'Creating Partnering space' Exploring the Right Fit for Sustainable Development Partnerships, the partnership recourse centre, Published in: Seitanidi, M. M. \& Crane, A. (eds). Social Partnerships and Responsible Business. A Research Handbook. Routledge. (2013) 